\title{
Notas biográficas
}

\section{Enrique Eduardo Fernández Ferreira}

Intendente mayor. Jefe de la Guardia Urbana de Tarragona. Doctor en Antropología Urbana por la Universitat Rovira i Virgili. Máster en Seguridad por la UNED. Licenciado en Psicología por la Universidad de Santiago de Compostela. Diploma Superior en Psicología Militar (Ministerio de Defensa). Ha colaborado en la docencia con la Universidad de Barcelona, con la Universitat Rovira i Virgili, y con la Escuela de Policía de Cataluña. Es autor de diversas publicaciones sobre distintos aspectos de las políticas de seguridad.

\section{Anabel Garrido Ortolá}

Profesora Asociada de Sociología en la Universidad Complutense de Madrid (UCM) y profesora colaboradora de la Universitat Oberta de Catalunya (UOC). Ha sido Investigadora Asociada (2009-2017) en el Área de Género del Instituto Complutense (ICEI-UCM). Doctora en Sociología y Antropología (2017) y posgraduada en: Máster en Desarrollo y Ayuda Internacional (ICEI-UCM) y Máster Oficial en Relaciones Internacionales (UCM). Ha trabajado como técnica en la Agencia Española de Cooperación Internacional para el Desarrollo (AECID) en la Oficina de Colombia y como consultora en ONG. Sus principales líneas de investigación se centran en Movimientos Sociales, Conflictos y Seguridad desde la perspectiva de género.

\section{María Gavilán Rubio}

Magistrada-Juez. Licenciada en Derecho por la UCM. Ejerce docencia en el Centro Universitario María Cristina (UCM) y docencia especializada en la Escuela Judicial y en distintos centros formativos de Cuerpos de Seguridad. Ha realizado actividades formativas para jueces y fiscales de Reino Unido, Bélgica, Bolivia, Ecuador y Guinea Ecuatorial. Es colaboradora de UNODC, la Oficina de Naciones Unidas contra la Droga y el Delito; así mismo ha colaborado en instituciones de la UE en formación y buenas prácticas judiciales en materia de trata de seres humanos. Es autora de diversas publicaciones tanto en el ámbito académico como profesional.

\section{Martín Sánchez Sánchez}

Inspector Jefe del Cuerpo Nacional de Policía. Licenciado en Ciencias Económicas y Empresariales por la UCM y Diplomado en Ciencias Policiales por la Universidad de Salamanca. Ejerce docencia especializada en diversos centros formativos de Cuerpos de Seguridad, así como en el ámbito de la judicatura y fiscalía. Es autor de diversos artículos profesionales.

\section{Pablo Enrique Rodríguez Pérez}

Director General de la Policía del Ayuntamiento de Madrid. Comisario del Cuerpo de Policía Municipal de Madrid. Doctor en Derecho y Licenciado en Criminología. Master en Dirección y Estratégica de la Seguridad Pública (URJC) entre otras titulaciones. Titulado Superior en Prevención de Riesgos Laborales. Diplomado en Defensa Nacional. Director de Emergencias y Protección Civil. Ejerce docencia especializada en diversos centros formativos de Cuerpos de Seguridad. Director del Centro de Formación de Seguridad y Emergencias del Ayuntamiento de Madrid. 


\section{Isabel Bazaga Fernández}

Profesora Titular de Universidad (Interina). Doctora en Ciencia Política por la Universidad Complutense de Madrid. Coordinadora del Grado en Ciencia Política y Gestión Pública de la URJC en la que dirige el Máster en Dirección Estratégica de la Seguridad Pública. Investigadora permanente del Instituto Universitario de Investigación Ortega y Gasset. Es miembro del comité científico de CIFAL en el programa para la prevención de la radicalización violenta. Asimismo, forma parte del equipo del Observatorio de Buena Gobernanza de la URJC. En la actualidad es investigadora principal en el proyecto JP-COOPS (Judicial and Police Cooperation Preventing Radicalization Towards Terrorism) financiado por la Comisión Europea en el marco del programa JUST (Poject: 807032 JUST-JTRA-EJTRAG-2017).

\section{Rut Bermejo Casado}

Profesora contratada doctora de Ciencia Política de la Universidad Rey Juan Carlos. Directora del Máster en Perfiles Forenses de Peligrosidad de la URJC. Miembro del Consejo Asesor de la Cátedra de Refugiados y Migrantes Forzosos de la UPCO. Miembro del Observatorio de Igualdad de la URJC y Secretaría Académica del Observatorio de Buena Gobernanza de la URJC. Es investigadora principal del proyecto PRACTICIES (Prevención de la radicalización violenta de los jóvenes en las ciudades) financiado por la Comisión Europea dentro del programa H2020 (Project 740072 H2020-SEC-2016-2017-1).

\section{Manuel Tamayo Sáez}

Profesor Contratado Doctor de Ciencias Políticas de la Universidad Rey Juan Carlos. Investigador del Instituto Universitario Ortega y Gasset desde 1988. Licenciado en Sociología (UCM) y Diplomado en investigación social aplicada y análisis de datos (ECPR). Doctorado por la Universidad Complutense en el año 2002. Miembro del equipo del Observatorio de Buena Gobernanza de la URJC. En la actualidad es investigador principal del proyecto CEDAR (Continuing Education Against Radicalisation) financiado por la Comisión Europea dentro del programa ERASMUS $+(\mathrm{KA} 203-8004 \mathrm{C} 65 \mathrm{E})$. 